\title{
Rural and Remote Health
}

The Intemational Electronic Joumal of Rural and Remote Health Research, Education, Practice and Policy

\section{PROJECT REPORT \\ TB questions, East Kwaio answers: community-based participatory research in a remote area of Solomon Islands}

\author{
PD Massey ${ }^{1}$, J Wakageni ${ }^{2}$, E Kekeubata ${ }^{3}$, J Maena'adi ${ }^{3}$, J Laete'esafi ${ }^{3}$, J Waneagea ${ }^{3}$, G Fangaria ${ }^{2}$, C Jimuru $^{2}$, \\ M Houaimane ${ }^{2}$, J Talana ${ }^{3}$, D MacLaren ${ }^{4}$, R Speare $^{4}$ \\ ${ }^{1}$ Health Protection, Hunter New England Population Health, Tamworth, New South Wales, \\ Australia \\ ${ }^{2}$ Atoifi Adventist Hospital, Malaita, Solomon Islands \\ ${ }^{3}$ Community member, East Kwaio, Malaita, Solomon Islands \\ ${ }^{4}$ School of Public Health, Tropical Medicine and Rehabilitation Sciences, James Cook University, \\ Townsville, Queensland, Australia
}

Submitted: 13 March 2012; Revised: 31 July 2012, Published: 24 October 2012

Massey PD, Wakageni J, Kekeubata E, Maena'adi J, Laete'esafi J, Waneagea J, Fangaria G, Jimuru C, Houaimane M, Talana J, MacLaren D, Speare R

TB questions, East Kwaio answers: community-based participatory research in a remote area of Solomon Islands Rural and Remote Health 12: 2139. (Online) 2012

Available: http://www.rrh.org.au

\section{A B S T R A C T}

Introduction: East Kwaio is a remote region on the island of Malaita, Solomon Islands. Atoifi Adventist Hospital (the Hospital) is the only hospital and tuberculosis (TB) services provider in the region. If people come to the Hospital with TB, they are usually admitted for the two-month intensive phase of treatment as there are no community-based TB services. Most people walk or travel by canoe to the Hospital as there are no roads. East Kwaio is known to have high rates of TB; however, it has a low case detection rate and low treatment completion. The aims of this study were to explore why people with TB, especially from the mountain areas, present to the Hospital so late in their illness or do not present at all. The study was part of a larger project to strengthen the research capacity of local health workers and community leaders, supported by visiting researchers from Australia.

Methods: Semi-structured interviews with TB patients, a focus group of key informants and direct interaction with a community with a history of TB were used to explore reasons why people present to the Hospital late in their TB illness. 
Results: Four interviews and a focus group of 12 key informants were conducted and a mountain hamlet with a history of TB was visited. The results represent the data from the interviews and the focus group. The time delay in presenting to the Hospital from when participants first became unwell ranged between two and three years. In the mountain hamlet, two additional people with probable TB were seen who had not presented to the Hospital during illnesses of five and nine months. Reasons for delays included: seeking care from traditional healers; the challenge of accessing health services due to distance, cost and cultural issues different from the Hospital's worldview; social isolation when in hospital; and being old so not having long to live. Delays in diagnosis of people with $\mathrm{TB}$ will increase the risk of transmission to family and through hamlets and villages. This study has led to plans being developed to build a more culturally appropriate TB ward and community treatment program.

Conclusions: The study has identified TB questions that need East Kwaio answers. It has shown that a small project can inform the development of important changes to TB services, such as the redevelopment and relocation of the TB ward. To enable TB control, the local health services need to develop an understanding of, and appropriately engage with, traditional beliefs that influence how people interact with Hospital TB treatment and management. This is the case even if the beliefs are based on a worldview different than that of the health service providers. Ongoing operational research is required into TB diagnosis and treatment services and the many factors that contribute to the high TB burden in this remote area.

Key words: community-based participatory research, operational research, public health, resource-limited community, Solomon Islands, tuberculosis.

\section{Introduction}

Can small research projects carried out by local teams in developing countries with minimal funding provide insightful answers to local questions? Encouraged by success in theoretical training in operational research at Atoifi Adventist Hospital (the Hospital), Malaita, Solomon Islands in 2009, local community leaders and health workers partnered with visiting Australian health researchers to form a number of research teams to conduct small projects to explore local health questions ${ }^{1,2}$. In this article, we describe how local answers were able to address local questions about tuberculosis (TB).

Solomon Islands is a developing country with one of the highest burdens of $\mathrm{TB}$ in the Pacific Islands. Papua New Guinea has the highest rates of TB in the Pacific, but due to the relatively large population, the $\mathrm{TB}$ rates are routinely analysed separately to other Pacific countries ${ }^{3}$. For the period 2007-2009, Solomon Islands reported 365-397 notifications of TB annually at a rate of $128 / 100,000$ population $^{3}$. Within the Pacific Islands, Solomon Islands accounts for $18 \%$ of the population but $26 \%$ of the TB burden, with a case detection rate of just $50 \%{ }^{3}$. According to the National TB Program of the Solomon Islands, the island of Malaita has high rates of TB (115/100 000 pop) with low TB case detection and low treatment completion rates, particularly in the remote central and eastern regions served by Atoifi Adventist Hospital (N Itago, pers. comm., 2011).

Atoifi Adventist Hospital is a 90-bed general hospital located in East Kwaio on the remote eastern coast of Malaita, Solomon Islands. It is the only hospital and TB services provider in the eastern region of Malaita. If people come to the hospital with TB they are usually admitted for the initial two-month intensive phase of treatment, then sent home with the four-month continuation phase treatment. There are currently no community-based TB services in Malaita, including no DOTS (Direct Observed Treatment Shortcourse). There are no roads to the Hospital or in the area.

The Hospital serves the approximately 10000 people in the East Kwaio region of East Malaita, most of whom live a 
subsistence life in coastal villages and predominantly practise Christian religions. Approximately 3000 people live in small hamlets in the mountainous interior of Malaita and predominantly practise ancestral religion ${ }^{4}$. Most people walk or travel by canoe to the Hospital; this can take up to three days. In recent years there has been a concerted effort to embed operational research as a way local health professional and community leaders can actively engage with, understand and address public health challenges in the area ${ }^{2,3}$. This effort included theoretical training in operational research in 2009 and follow-up practical health research workshops in April and October 2011 and April 2012. These utilised a community-based participatory research framework ${ }^{5,6}$, and decolonising methodologies ${ }^{7,8}$, to explore a number of health issues including operational issues of $\mathrm{TB}$ treatment and management in East Kwaio.

In the Pacific context, there is little published operational research in TB. A single report indicated that a computerised TB Register improved the TB treatment program in the Solomon Islands capital ${ }^{9}$. Actively engaging with community leaders and traditional healers about TB was found to be an important issue in a review of TB treatment programs in four Pacific countries ${ }^{10}$. This review also found that addressing barriers to transport for people living in the outer islands was needed. International evidence also emphasises that delayed diagnosis and treatment results in increased transmission in the community ${ }^{11}$.

The aims of this study were to explore why people with $\mathrm{TB}$, especially from the mountain areas, present to the Hospital so late in their illness or do not present at all. The study was part of a larger project with the following objectives: to develop appropriate research methods and strengthen research capacity of local health workers, community leaders and visiting health researchers through investigating local health concerns. Investigations were designed to inform health services to reduce the burden of disease in an appropriate way for the people of East Kwaio.

\section{Study population, design and methods}

A team comprising health professionals from the Hospital and Atoifi College of Nursing, Tribal or Village chiefs, community and church leaders, and public health researchers from Australia participated in the research capacity strengthening workshop. The team included chiefs with more than 40 years of experience in partnering with visiting researchers. In addition, community and church leaders active in advocating for improved community health outcomes and health service professionals, including the TB coordinator for East Malaita, were part of the team. The visiting health researchers from Australia had more than 30 years of experience in public health research in the Pacific region, including 20 years of experience at Atoifi. All members of the team described $\mathrm{TB}$ as an important health issue that was badly affecting the people of East Kwaio and indicated that TB deserved increased research attention.

This study used two methods to explore why people with signs and symptoms suggestive of TB do not seek treatment or delayed seeking treatment at the local hospital. These methods were: (i) semi-structured interviews with $\mathrm{TB}$ patients; and (ii) a semi-structured interview and a focus group with key informants. Using a purposive sample, three patients with $\mathrm{TB}$ were identified through the Hospital records, one each from a coastal village, a village some way up the mountain slope and a remote mountain hamlet. The most recently discharged patients from each of the areas of interest were chosen. At the time of the study, only two patients of the 15 officially recorded TB cases at the Hospital in 2011 were admitted and on treatment. The interview team for the patient interviews consisted of a Chief, who was the cultural broker, and two local male nurses to ensure cultural acceptability of the research. In addition the mountain Chief from the team was interviewed by the lead researcher.

The patients were asked to describe: (i) when they first became unwell with TB; (ii) when they first went to the Hospital; and (iii) what were the reasons for not presenting to 
the Hospital earlier. The Chief was asked the same questions about a family member. The interviews were conducted in the local language of East Kwaio and/or in Solomon Islands Pijin, recorded on digital recording devices, transcribed and analysed. Interviews lasted 10-30 minutes. The data were analysed by the research team together, in Kwaio language and Solomon Islands Pijin, for shared experiences with data coded inductively using a thematic coding scheme ${ }^{12}$. Common and differing themes were identified and findings were translated into English. In addition, since the research team contained local chiefs from the coast and the mountains, explanations made by the interviewees could be interpreted during the analysis process and placed in the context of the interviewees' worldviews.

The focus group of 12 key informants occurred some months after the interviews and was conducted at a mountain hamlet of one of the chiefs in the team. This was more than half a day's walk into the mountains. The focus group included other chiefs and important people from the surrounding hamlets. The focus group was asked to discuss reasons why people did not present to the Hospital when sick with symptoms of TB. The focus group was conducted in the local language of East Kwaio and/or in Solomon Islands Pijin. The comments were digitally recorded. The stories were then translated into English by two of the team members. The research team was invited by the chiefs to visit a nearby hamlet known to have a history of $\mathrm{TB}$ in order to interact with the community and talk with two men who had symptoms consistent with $\mathrm{TB}$ but who had not gone to the Hospital.

Results of the study were presented to an open community meeting and were presented by investigator CJ at the Annual Solomon Islands TB Workshop in the capital, Honiara. Following decolonising principles of local community involvement at all stages of research, authors gathered at Atoifi in October 2011 and again in April 2012 to write and review this article in preparation for submission for publication.
Ethics approval was given for the research project by the Atoifi Adventist Hospital Ethics Committee (AAHEC2), Ministry of Health and Medical Services, Solomon Islands and the James Cook University Human Research Ethics Committee (H4002).

\section{Results}

Four interviews followed by a focus group of 12 key informants were conducted, and a mountain hamlet with a history of TB was visited. The focus group consisted of three chiefs, eight men and one woman from surrounding hamlets.

Delays in presenting to the Hospital for diagnosis and treatment from when the three interview participants first became unwell ranged between two and three years. In addition, during the focus group and interview with a chief from the mountain areas it was revealed that at least seven people known to participants did not go to the Hospital at all. The people all had symptoms consistent with TB.

The reasons for this delay that emerged from the interviews included: seeking care from traditional healers; the challenge of accessing health services due to distance, cost and cultural issues; social isolation when in hospital; and being old so not having long to live.

\section{Delay due to utilisation of traditional healers}

Traditional healers were a part of the story for two of the participants. Local people when faced with illness often consult healers and are prescribed a variety of traditional medicine. When traditional medicine prescribed for these two participants eventually did not work, hospital treatment was sought. This meant delays in diagnosis and treatment with hospital medicine. One participant described taking traditional medicine when the hospital medicine did not work. This patient had received the routine two-month treatment in the Hospital and was then discharged home for the unsupervised continuation phase. It is not clear whether he completed the continuation phase prior to becoming 
unwell again, although he explained that he took traditional medicine for a three-year period before returning to the Hospital for more hospital treatment.

No, mi feel sick nao mi come, so 2007 mi go back yia nao me drink meresim go go finish but sem sem no moa, so 2008, 2009 and 2010 me takem lele bet Custom meresin go go finish but hem sem sem no moa. No something olsem nao yon duim by gud, so me dinim go but sem sem no moa, so there nao mi come back.

No, I felt sick then I came [to the Hospital], so back in 2007 I come and take medicine until finished, but I felt the same after, so in 2008, 2009 and 2010 I take traditional medicine and finished that, but still feel the same. There is no such thing like this that will make you good, but I did it anyway, but it was the same, so that is when I came back. (Translated)

\section{Delay due to difficulties in accessing Hospital services: distance}

All participants described distance to the Hospital as a problem. As one participant said: 'Many people live in remote locations, up to three days walk in the mountains' (translated).

\section{Delay due to difficulties in accessing Hospital services: cost}

Participants described cost as an important challenge for them in accessing health services at Atoifi. One participant said that they 'don't have enough money for transport [to pay for hire of canoe with outboard motor, fuel and driver] to get to the Hospital' (translated) or to buy food when at hospital for a long time. One participant described how he had to 'sell pigs to get cash for transport and to buy food while in Hospital' (translated). For people from the mountains, costs associated with cultural issues were particularly high.

\section{Delay due to difficulties in accessing Hospital services: cultural taboos}

For the people who practise ancestral religion, there are important spiritual/cultural reasons for why accessing the Hospital services is difficult. One participant described the situation as:

\begin{abstract}
Becos no ani seleni, hem farawe. Wanem mi doim so mi mekem lo saed lo kastom nao. Olsem sekrifaes den faendim seleni befor mi kam. Wans mi no faendim seleni, had for kam nao ia. Cos far awe den fea blo kanu hem tumas ia. So 10 fala pig. Sekrifaes for mi kam lo hia for no ani ting for stopim medicin mi tekem ia. Supos if mi no sekrifaes nomata mi tekem how mani fala medicin sai bae no woka. Des wai mi mekem sekrifaes for mekim olketa medicin mi usim hemi woka.

Because no money and it [the Hospital] is faraway. So what I did was to make things right with custom. Like sacrifice, then find money before I came. If I did not find any money it would be hard for me to come. Because it is far away and then fare for the canoe is just too much. So 10 pigs. I sacrificed so I could come here [the Hospital] and nothing would stop the medicine I would take. If I did not sacrifice, even if I took lots of medicine, it would not work. That's why I made the sacrifice to make the medicine I take to work. (Translated)
\end{abstract}

The participant described that he needed to get permission to go into the TB ward from deceased ancestors. This is because the ward is situated next to, and its roof connected to, the taboo maternity ward, a place men cannot go close to, or even see, in mountain hamlets. Going into a building connected to the maternity ward causes ancestral anger requiring an offering to the ancestors before entering the $\mathrm{TB}$ ward and reconciliation with the ancestors after leaving the TB ward on return to his hamlet. This cost the participant 10 pigs before entering the TB ward and 10 pigs as sacrifices after going back to his mountain hamlet.

The mountain chief interviewed also reported the same story about his relative. This relative did not present at all to the Hospital because of the cultural issues of the location of the 
TB ward. This same story was repeated another four times at the focus group in the mountain areas. Each of these participants knew of people who had not attended the Hospital for TB treatment. Some of these people had subsequently died from the illness. In addition, the team saw two men with probable $\mathrm{TB}$ during the field trip into the mountain areas. Each man said that he could not attend the Hospital for the same reasons, even though the men had been sick for five months and nine months, respectively. The person who had been sick for nine months was very unwell and was assessed by a TB nurse as unlikely to survive unless treated. The chiefs reported he died in his hamlet in the month following the team's visit.

\section{Social isolation while in hospital}

Social isolation at the Hospital was a common theme and caused people to be reluctant to be admitted. One participant explained that when he went to hospital he had no 'wantoks' and so was very lonely, with no one to care for him or talk with him. 'Wantoks' are people who speak the same language and are often extended family from the same village/hamlet or area.

\section{Too old}

Being old so not having long to live was also described as a reason for coming to the Hospital late in the illness and ignoring the advice of the doctor.

Ki kooko'o no'o 'ola bala alata ada no'o 'aki mae no'o. Gwa'a ki go'ugo'u melesini ma 'ola te'e 'ato mola.

I am old now, and maybe it is my time to die; even if I take medicine it won't make any difference. (Translated)

Dokita e maakemnau la'u ma ka ngarinau na X-ray. Ma ka kwairii no'o darinau. Ma 'ola abulo'onga ada mola.

The doctor reexamined me and took me to the X-ray. And he told me. But I just ignored what he said. (Translated)
All of the issues raised by our interviewees were also spoken of by the people participating in the focus group in the mountains, indicating that these were commonly experienced and understood phenomena in the East Kwaio community.

\section{Discussion}

The importance of TB as a health issue to the people in this region was highlighted by the strength of community engagement with research capacity building activities. Chiefs, community leaders, teachers, nurses and health workers devoted weeks of time to learn more about research and conduct the project. The project explored some of the operational reasons why TB is challenging to control in this area and demonstrated that the methods were sound.

The Australian investigators had initially suggested that a valuable question would be to investigate $\mathrm{TB}$ treatment compliance. However, the local researchers proposed an alternative question of more concern to them for this study. This change of research focus demonstrates the strong engagement of the local health professionals and community leaders as a result of the research strengthening aspect of the project.

Investment and capacity building in operational research within the type of resource-limited setting of this project is crucial in determining how to apply locally relevant $\mathrm{TB}$ control strategies so that health care can become more acceptable and efficient ${ }^{13}$. In low-income countries, operational research has a key role in filling the gap between what we know from research and what we do with that knowledge ${ }^{14}$.

Research into TB has historically mainly focused on the agendas of academics and the science of diagnosis and treatment, and reflected particular Western interests ${ }^{15}$. To counter this dominant developed world paradigm, it has been suggested that a relevant research agenda in developing settings be built. As occurred in this remote setting in a developing nation, it is necessary to start small and then 
engage local and external institutions as equal partners ${ }^{13,15}$. Local health leaders and community leaders forming locally relevant TB questions and finding East Kwaio answers, whilst strengthening research capacity, through partnerships with some Australian researchers illustrates operational research in action.

A number of issues that require continued immediate action and further inquiry have been identified in this project. Engaging traditional healers with health services and older people's reluctance to seek help appear to be important issues. Distance to the Hospital is also a factor in delays in treatment and possible ongoing transmission of $\mathrm{TB}^{10}$. Supervision of the continuation phase and community-based services may address some of the issue of why people delay returning for care. As there is currently no community-based TB service in East Malaita, including no DOTS, the development of such a service could be tested in this setting to improve access to TB diagnosis and treatment.

Delays in diagnosis of people with TB will increase the risk of transmission to family and throughout hamlets and villages. This study, consistent with previous local public health research $^{4,16}$, has identified complex health service and cultural issues that hinder access to health services. This study raised issues about culturally appropriate Hospital building design to improve access. Depending on the number of ancestors people actively worship, people from the mountain areas may need to sacrifice more than ten pigs to come to the Hospital and this will be a large barrier. Ten pigs cost the equivalent of 2-4 months of wages for a local worker; for those without access to money, it may take many months or years to breed the pigs.

As a result of the research work, the Hospital has now started planning where and how to construct a TB ward that is better positioned and more appropriate for all of the local cultures. Health service providers must continue to change the way services are delivered to take into account traditional beliefs that would otherwise impede access to the Hospital's TB treatment and management. This is the case even if the beliefs are based on a worldview different to that of the health-care provider $^{4,16}$. The Hospital is now providing an integrated primary health-care service (including TB services) into some mountain areas. Community-based TB treatment models are also being considered. There is an opportunity to expand this though the seven clinic and health posts in East Kwaio that link with the Hospital and are supported by the Hospital's primary health-care outreach team.

There were a number of limitations experienced in this project, including that samples may not have been representative; a small number of participants were involved; and some researchers were learning research skills as they conducted the research. But the strengths are that the work was clearly community-based and there was a high level of community involvement and interest in the work and in improving health. Community leaders and health professionals stated results were consistent with their experience, which was further confirmed in community meetings. This is the first reported study on reasons for delays to TB diagnosis in the Solomon Islands.

\section{Conclusion}

This community-based study has identified TB questions that need East Kwaio answers and has shown that a small project can bring about important changes. Continuing to strengthen research capacity locally has strong support from the communities involved. Immediate action is now occurring and needs to continue to address some of the factors that influence the high TB burden experienced in East and Central Malaita. This includes more appropriate access to diagnosis and treatment services. Ongoing operational research is required into these and other factors that contribute to the high TB burden in this remote area of Solomon Islands. This study, although small, illustrates that research done by local researchers in a remote area of a developing country with minimal resources can provide useful answers to local questions.

(C) PD Massey, J Wakageni, E Kekeubata, J Maena'adi, J Laete'esafi, J Waneagea, G Fangaria, C Jimuru, M Houaimane, J Talana, D MacLaren, R Speare, 2012. A licence to publish this material has been given to James Cook University, http://www.rrh.org.au 


\section{Acknowledgements}

The authors acknowledge and thank Dr David Akin for his expert advice on Kwaio language and translation. The authors also thank Michelle Redman-MacLaren for her support and expert advice on the manuscript. This work was supported in part by a Research Infrastructure Block Grant, School of Public Health, Tropical Medicine and Rehabilitation Sciences, James Cook University, the Anton Breinl Centre Wildlife Services Fund, and in-kind support from NSW Ministry of Health and Atoifi Adventist Hospital.

\section{References}

1. Redman-Maclaren ML, Maclaren DJ, Asugeni R, Fa'anuabae CE, Harrington H, Muse A et al. 'We can move forward': challenging historical inequity in public health research in Solomon Islands. International Journal for Equity in Health; 2010; 9: 25.

2. Redman-Maclaren ML, Maclaren DJ, Solomon J, Muse A, Asugeni R, Harrington $\mathrm{H}$ et al. Research workshop to research work: initial steps in establishing health research systems on Malaita, Solomon Islands. Health Research Policy and Systems 2010; 8: 33.

3. Viney K, O'Connor J, Wiegandt A, Lambert M, Cox H, Downing S. Tuberculosis trends in the Pacific 2000-2006. Pacific Health Dialog 2010; 16(1): 157-171.

4. MacLaren D. Culturally appropriate health care in Kwaio, Solomon Islands. An action research response. Brisbane, QLD: Griffith University, 2007.

5. Wells K, Jones L. 'Research' in community-partnered, participatory research. JAMA 2009; 302: 320-321.

6. Cornwall A, Jewkes R. What is participatory research? Social Science and Medicine 1995; 41: 1667-1676.
8. Denzin NK, Lincoln YS, Smith LT. Handbook of critical and indigenous methodologies. Thousand Oaks, CA: Sage, 2008.

9. Carroll K, Malefoasi G. Comparison of outcomes from a district tuberculosis control programme in the Pacific: before and after the implementation of DOTS. Tropical Doctor 2004; 34: 11-14.

10. Massey PD, Viney K, Kienene T, Tagaro M, Itogo N, ItuasoConway $\mathrm{N}$ et al. Ten years on: highlights and challenges of directly observed treatment short-course as the recommended TB control strategy in four Pacific Island nations. Journal of Rural and Tropical Public Health 2011, 10: 44-47.

11. Lonnroth K, Jaramillo E, Williams B, Dye C, Raviglione M. Tuberculosis: the role of risk factors and social determinants. In: E Blas, A Sivasankara Kurup (Eds). Equity, social determinants and public health programmes. Geneva: WHO, 2010.

12. Minichiello V, Aroni R, Hays T. In-depth interviewing. Sydney, NSW: Pearson Education, 2008.

13. Zachariah R, Harries AD, Ishikawa N, Rieder HL, Bissell K, Laserson $\mathrm{K}$ et al. Operational research in low-income countries: what, why, and how? Lancet Infectious Diseases 2009; 9: 711-717.

14. Zachariah R, Ford N, Maher D, Bissell K, Van den Bergh R, van den Boogaard $\mathrm{W}$ et al. Is operational research delivering the goods? The journey to success in low-income countries. Lancet Infectious Diseases 2012; 12: 415-421.

15. Harries AD, Rusen ID, Reid T, Detjen AK, Berger SD, Bissell $\mathrm{K}$ et al. The Union and Médecins Sans Frontières approach to operational research. International Journal of Tuberculosis and Lung Disease 2011 ; 15(2): 144-154.

16. MacLaren D, Asugeni J, Asugeni R, Kekeubata E. Incoroporating sociocultural beliefs in mental health services in Kwaio, Solomon Islands. Australasian Psychiatry Journal 2009; 17(1): S125 -S127.

7. Smith LT. Decolonizing methodologies: research and indigenous peoples. London: Zed Books, 1999.

(C) PD Massey, J Wakageni, E Kekeubata, J Maena'adi, J Laete'esafi, J Waneagea, G Fangaria, C Jimuru, M Houaimane, J Talana, D MacLaren, R Speare, 2012. A licence to publish this material has been given to James Cook University, http://www.rrh.org.au 